\title{
Monitoring the Patient Following Radio-Cephalic Arteriovenous Fistula Creation: Current Perspectives
}

This article was published in the following Dove Press journal: Vascular Health and Risk Management

\author{
Nicola Pirozzi ${ }^{1}$ \\ Nicoletta Mancianti ${ }^{2}$ \\ Jacopo Scrivano' \\ Loredana Fazzari ${ }^{1}$ \\ Roberto Pirozzi \\ Matteo Tozzi ${ }^{3}$ \\ 'Interventional Nephrology Unit, \\ Nephrology and Dialysis Department, \\ CdC Nuova ITOR, Roma, Italy; \\ ${ }^{2}$ Nephrology, Dialysis and Transplant \\ Unit, University Hospital of Siena, Siena, \\ Italy; ${ }^{3}$ Vascular Surgery, University of \\ Insubria - Asst Settelaghi Varese, Varese, \\ Italy
}

\begin{abstract}
Autogenous radial-cephalic direct wrist arteriovenous fistula (RC-AVF) in the non-dominant arm is the gold standard for dialysis vascular access. However, the RC-AVF non-maturation rate is significant $(\simeq 40 \%)$ due to an increasingly elderly and comorbid population incidence. A detailed identification of the biological cascade underlying arteriovenous fistula (AVF) maturation could be the key to clinical research aimed at identify the group of patients at risk of primary AVF failure. Currently, careful post-operative monitoring remains the most crucial aspect to overcome the problem of impaired maturation. Up to $80 \%$ of patients with immature RC-AVF have problems potentially solvable with early endovascular or surgical correction. Physical examination by experienced practitioners in conjunction with duplex ultrasound examination (DUS) can identify physical signs of non-maturation, understand the underlying cause, and drive for a tailored early planning to treat the complication. New approaches for the early assessment of AVF maturation are under study. Techniques to promote RC-AVF maturation performed through the administration of pre-or peri-operative drugs have missed up to now to prove an efficacy in improving fistula success. The new techniques tested after surgery appear to hold future promise for improving fistula maturation.
\end{abstract}

Keywords: arteriovenous fistula maturation, hemodialysis, early failure, rule of six, vascular access

\section{Introduction}

End stage renal disease (ESRD) management by chronic hemodialysis (HD) requires the ready and iterative blood access from circulatory system, able to provide high flow rate. Autogenous arterio-venous fistulae (AVF) have been recognized as the primary and best hemodialysis vascular access option for ESRD patients who require renal replacement therapy by HD. ${ }^{1}$ AVF is a surgically created arterio-venous anastomosis by which high pressure arterial blood is diverted into the high-capacity venous system. Pressure drop leads to blood velocity increase and finally to vessel dilatation and wall thickening along with blood flow increase; thus, enough blood flows is obtained to carry out an effective HD treatment.

As to the recommendation of the National Kidney Foundation (NKF) Dialysis Out-comes Quality Initiative (DOQI) ${ }^{2} /$ European Society for Vascular Surgery $(\text { ESVS })^{3} /$ European Renal Best Practice (ERBP) ${ }^{4}$ guidelines, autogenous radialcephalic direct wrist arteriovenous fistula (RC-AVF) in the non-dominant arm, should be the first choice when an angioaccess is needed. It exhibits better
Correspondence: Nicola Pirozzi Interventional Nephrology Unit, Nephrology and Dialysis Department

CdC Nuova ITOR, Via di Pietralata I62, Rome, 00I58, Italy

Email nicola.pirozzil@gmail.com
Vascular Health and Risk Management 202I:I7 III-12I

| | |

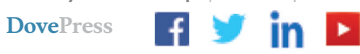


functionality, with lower incidence of infections and longterm complications, as compared to central venous catheters (CVC) and arteriovenous grafts (AVG), respectively. Ideally, a peripheral-central sequence (distal to proximal) of fistula construction should be provided, starting with the "snuff box" fistula or more commonly with the wrist fistula (Brescia-Cimino AVF), ${ }^{5}$ followed by a cephalic fistula at mid forearm and finally a proximal cephalic fistula in the upper third of the forearm. If this is not possible, a brachio-cephalic AVF would usually be the next choice. The brachio-basilic AVF associated with vein superficialization usually represent the last autogenous choice on the arm. Lastly humero-humeral or femorofemoral AVF with vein superficialisation are between some more exotic autogenous angioaccess for HD. ${ }^{6-8}$

The gold standard angioaccess for chronic HD, the RCAVF fistula, suffers from an elevated rate of nonmaturation, thus a careful monitoring after surgery should be implemented in order to face at the best this potential early complication.

The aim of this review is to analyze the maturation model of the RCAVF, risk factor for impaired maturation and the strategies to maximize the proportion of treated patients achieving a functional patent angioacces.

\section{Arteriovenous Fistula Maturation: Physiology}

Maturation is the remodeling process by which an AVF becomes suitable for cannulation and provide sufficient blood flow for adequate hemodialysis. AVF formation involves a direct connection of an high pressure pulsatile flow conduit (artery) to a low pressure steady flow conduit (vein). ${ }^{9}$ Elevation of blood flow rate is responsible for rapid increase in wall shear stress (WSS), the traction stress induced by velocity gradient on the luminal vessel surface. Data show that the WSS of the vein after the creation of the RC-AVF increases from $1-6 \mathrm{dyn} / \mathrm{cm}^{2}$ to 10-70 dyn $/ \mathrm{cm}^{2}$, such as the level of the arterial system. ${ }^{9}$

This pressure stimulus in the vein result in adaptive responses of remodeling of the vein wall, including structural and functional reorganization. Detailed studies suggest that the AVF maturation process depends on the prevalent modality of remodeling that the venous vessel undergoes. $^{10,11}$

From a biological point of view, the maturation of AVF is related to the response of endothelial cells to changes in WSS. ${ }^{12,13}$ Specifically, to restore the WSS values, the venous vessel is remodeled in two ways: on the one hand, by increase neointimal cell deposition (inward remodeling) on the other, by eccentric medial hypertrophy resulting from increased circumferential tension due to flow mediated dilation rather than the elevated pressure alone (outward remodeling). If the prevailing process is outward remodeling, the AVF will successfully mature. On the contrary, excessive inward remodeling will lead AVF to failure maturation because of the occurring stenosis. ${ }^{14}$ The most common site of stenosis after AVF creation is found near the anastomotic segment but can also be observed all along the draining vein. Sites of previous vein injury (intravenous punctures) as well as venous valves may impede outward remodeling and can represent sites of stenosis. From a strictly histological point of view, neointimal lesions are caused by proliferation and migration of vascular cells. The pathological role of local cells residing in the vein has already been demonstrated. Other studies however suggest instead a role of fibroblast cells migrated from the arterial side. ${ }^{15,16}$

Several factors are involved in the AVF maturation: some non-modifiable along with some modifiable. The non-modifiable factors are those patient-specific, such as the age, co-morbidities, cardiac output, blood pressure, etc, and those due to the condition of the vessels. The vessel factors include arterial and venous network topology and geometry, length and diameter of the segments of the vein, elasticity and conformity of the walls of the vessels, preand postoperative radial artery disease, lesion factors (stenosis number, location and severity).

Other factors, potentially modifiable, that influence the maturation are the nitric oxide signaling (NOs) and the AVF flow. NOs induces the production of metal-proteinase matrix on endothelial cells allowing outward remodeling. As evidence of this, the genetic deficiency of NOs in a mouse model of AVF, compromises outward remodeling. ${ }^{17}$ Recent studies show that also uremia condition compromises the NOs pathway. ${ }^{18,19}$

Another factor that contributes to the remodeling phenotype is the AVF flow. Srivastava et $\mathrm{al}^{20}$ suggests that if the AVF shunt causes unstable flows characterized by fast intensity fluctuations and direction, changes in biological vascular cells will induce a predominantly inward remodeling which will prevent vein dilation and further increase in blood flow as needed in AVF maturation. On the contrary, when arteriovenous shunt induces a more undisturbed laminar flow the remodeling will be mainly external and the AVF will mature successfully. Furthermore, unstable flow can 
reduce the expression of NOs, already quite compromised in uremic patients, as mentioned above.

There are only limited studies focusing on physiopathology of AVF maturation. A more detailed identification of the biological phenomena underlying the AVF maturation may become clinically important to increase maturation rates, as well as to identify the group of patients at risk of primary AVF failure.

\section{Factors Associated with AVF Maturation}

There are several risk factors that influence the outcome of the AVF. ${ }^{21}$ Age and diabetes mellitus have been showed to interfere with AVF maturation and to increase significantly the risk of AVF failure. ${ }^{22,23}$ Women usually have smaller vessels than men, which can result in poorer maturation and less long-term patency. ${ }^{24}$

The full list of risk factors associated with the maturation of AVF are summarized in Table 1.

Another non modifiable parameter that influences AVF maturation is size of the artery and vein. In the study of Mendes et $\mathrm{al}^{25}$ concerning RC-AVF when the diameter of the cephalic veins exceeded $2 \mathrm{~mm}$ the percentage of successfully matured AVF was 76\% while, if the diameter was less than $2 \mathrm{~mm}$, the success rate dropped to $16 \%$. M. A. Siddiqui et $\mathrm{al}^{26}$ have shown that a preoperative vein diameter greater than $2.5 \mathrm{~mm}$ resulted in a fivefold increase in fistula maturation compared to a vein size

\section{Table I Risk Factors for AVF Maturation}

\begin{tabular}{|l|}
\hline Risk Factors for AVF Maturation \\
\hline Demographic characteristics \\
Elderly age \\
Female sex \\
\hline Comorbidity \\
Diabetes \\
Obesity \\
Chronic hypotension. \\
Peripheral artery disease \\
Ca-P metabolism alteration \\
Thrombophilic diathesis \\
Vessels inadequacy \\
Previous cannulations/interventions of central or peripheral vessels \\
Drugs or vaso-injurious factors (steroids, chemo/radio-therapy) \\
Insufficient arterial or venous diameters \\
\hline Other factors \\
Surgeon inexperience
\end{tabular}

Abbreviations: AVF, arteriovenous fistula; Ca-P, calcium-phosphorus. less than $2.5 \mathrm{~mm}$. The results were also similar in the Brimble et al study ${ }^{27}$ with a cutoff value of $2.6 \mathrm{~mm}$.

Similarly, the arterial internal diameter also appears useful in the risk assessment of an AVF.

About the AVF-RC a minimum internal radial artery diameter of $2 \mathrm{~mm}$ is suggested by the guidelines (level of evidence B). However, it is possible to successfully create fistulas with diameters of up to $1.5-1.6 \mathrm{~mm}$ if the wall of the arterial vessel it is predominantly healthy preserved from calcification and shows a satisfactory reduction in the resistant index after release of the fist (the reactive hyperemia test).

In pediatric populations, excellent results have also been obtained for lower arterial diameters using microsurgery associated with preventive hemostasis. Few data are available in the adult population. Pirozzi et al reported $68 \%$ and $96 \%$ primary and secondary 1 year patency in adults ESRD with an internal diameter $<1.6 \mathrm{~mm}$ in the radial artery. ${ }^{28}$

In this multitude of risk or protective factors, the personalization of the access creation project is mandatory to avoid unsuccessful attempts. Based on this, preoperative DUS mapping is fundamental in planning successful vascular access. According to the guidelines of the European Vascular Surgery Society, ${ }^{3}$ preoperative DUS is recommended for all patients scheduled for AVF or AVG with a class I recommendation (level of evidence A).

In addition to the non-modifiable risk factors dependent on the patient and his comorbidities, there are also risk factors relating to the intervention itself which can obviously be optimized. In this context, the angle of creation of the anastomosis which may be partially manipulated by the surgeon, would seem important. Ene-Iordache et al, ${ }^{29}$ through the WSS analysis, showed that the angle of anastomosis affects the local disturbed flow and that acute angles $\left(30^{\circ}-40^{\circ}\right)$ would lead to less neointimal hyperplasia, both on the vein and on the side arterial.

Moreover, some studies seem to identify certain drugs as protective against the eventuality of causing early failure. The drugs analysed are antiplatelet/anticoagulant, calcium channel blockers (CCB) angiotensin converting enzyme inhibitor (ACE-I) and angiotensin II receptor blockers (ARB), statins, fish oil, prednisolone or phytochemical constituents (iontophoretic injection of Salvia miltiorrhiza).${ }^{30-32}$ Currently there are not enough evidence to recommend antiplatelet treatment to reduce AVF thrombosis or improve maturation. Double therapy (aspirin plus clopidogrel) and monotherapy with warfarin significantly 
increased the risk of bleeding. A long-debated issue in this field has also been the routine use of systemic heparinization to avoid early thrombotic AVF events. Following a significant meta-analysis on the most relevant studies on this topic, the conclusion was that systemic heparin had no effect on patency but significantly increased postoperative hemorrhage. ${ }^{33}$

This data is also reported in the 2018 guidelines of the European Society for Vascular Surgery (ESVS) which recommend avoiding the routine systemic use of heparin for this purpose. ${ }^{3}$ Regarding CCB and ACE-I in the DOPPS study, treatment with CCB was associated with better primary patency and therapy with ACE-I was associated with significantly better secondary fistula patency. ${ }^{34}$ Similarly, Chen et $\mathrm{al}^{35}$ in their analysis documented a prolonged primary patency within the population using CCB, ACE-I or ARB. Strong evidence however still lacks, and other prospective randomized trials are in need.

As to use of statins, fish oil, prednisolone or phytochemical constituents (iontophoretic injection of Salvia miltiorrhiza), clinical studies are not conclusive and their use is not recommended by European Renal Best Practice $(\text { ERBP })^{4}$ guideline vascular access. ${ }^{30-32}$

Some interesting results have been obtained in the field of exercise on the AVF hand.

F. Salimi and colleagues ${ }^{36}$ verified that the exercise of the AVF hand positively influenced the ultrasound parameters associated with the maturity and on the acceleration of the clinical AVF maturation. Fontseré et $a 1^{37}$ confirmed in their trial that a postoperative exercise program after AVF creation increased the clinical maturation of AVF in distal accesses.

Given these findings, the guidelines recommend that patients be encouraged to follow a hand-arm exercise program after $\mathrm{AVF}^{2-4}$

\section{The Importance of the RCAVF Maturation Monitoring}

Thirty years ago, the AVF primary failure rate was rather low: less than 1 to 2 patients out of 10 suffered from this complication.

In the last years, as ESRD population turned older with heavier comorbidity burden, RC-AVF have reached a primary failure rate of up to $40-50 \%$ in the worst scenario. $^{38,39}$

In this context it is important to consider that primary access failure has numerous and substantial consequences: it can delay the start of dialysis, increase the dependence from a catheter, impair the long term patency of the access, limit the number of anatomical sites for subsequent accesses and request further interventions to recover the failed access and try one new.

It also increases the costs of healthcare. This cost has been quantified in the US system at $\$ 8,000$ per patient per year equal to $15 \%$ of Medicare's end-stage renal disease expense. ${ }^{40}$ It is essential to improve monitoring of access maturity because up $80 \%$ of patients with immature RC-AVF have a potentially resolvable problems with endovascular or surgical correction. ${ }^{41}$

\section{Early Failure: Definition and Incidence}

The major obstacle to the successful creation of RCAVF is maturation. Approximately $20-50 \%$ of AVF fail to mature. ${ }^{42}$ Maturation usually occurs 4 to 6 weeks after the initial fistula surgery, but this period can vary with an average time that varies from 1 to 4 months.

"Early failure", "failure to mature", "impaired maturation" are all synonymous and are generically defined as the inability of an AVF to be used for dialysis because of thrombosis (non-patent AVF), delayed maturation (insufficient blood flow and/or inadequate dilation of AVF vessels) or pseudo delayed maturation. The latter means that the AVF have correctly improved diameter and blood flow, but functional patency is not achieved because of excessive depth of the vein over a thick subcutaneous tissue.

The failed to mature AVF often have one or more potentially repairable factors.

In immature RC-AVF for example, up to $80 \%$ can be recovered by endovascular or surgical correction. Muray Casas et al in their study ${ }^{41}$ showed how they achieved $78 \%$ rescued immature RC-AVF in pre-dialysis patients. Compared to an AVF that mature without re-intervention however, AVFs that require corrective surgery will be more subject to multiple procedures to maintain their patency and have a reduced cumulative survival. ${ }^{43}$ The most common cause of AVF early failure are postoperatively thrombosis or stenosis of both vein or artery (pre-existing or de novo occurred after surgery). ${ }^{44,45}$

Table 2 summarize the causes of early failure.

\section{Early Failure Assessment: Physical Examination and the Rule of Six}

Physical examination of a new AVF created between four to six weeks should be considered mandatory to assess 
Table 2 Causes of AVF Early Failure

\begin{tabular}{|l|}
\hline Summary Table on the Causes of Early Failure \\
\hline $\begin{array}{l}\text { Stenosis } \\
\text {-iuxta-anastomotic } \\
\text {-of the arterial inflow } \\
\text {-of the venous outflow }\end{array}$ \\
\hline $\begin{array}{l}\text { Thrombosis (sometimes occur immediately after surgery or resulting } \\
\text { from the presence of a stenosis). }\end{array}$ \\
\hline Central venous stenosis or thrombosis \\
\hline Hematoma and pseudoaneurysm \\
\hline Infection, seroma and lymphatic collection \\
\hline Steal syndrome and ischemic monomelic neuropathy \\
\hline Pseudo-delayed maturation \\
\hline
\end{tabular}

Abbreviation: AVF, arteriovenous fistula.

fistula maturation and detect any problems as soon as possible. Waiting longer than 4-6 weeks is generally not necessary and does not improve the chances of recovery of access. $^{46}$

The physical examination by expert physicians can identify physical signs of failure of maturation such as: absent or faint thrill, hyperpulsatile AVF, small diameter vein, excessive depth, large collateral veins and high pitch continuous systolic audible bruit. Clinical studies ${ }^{47-49}$ show that physical examination of the newly created AVF by an experienced practitioner has a greater than $80 \%$ accuracy in predicting AVF maturation. Despite this, ultrasound parameters (internal diameter, volume flow rate, depth) are recommended in conjunction with physical examination.

Table 3 summarizes the elements useful to the execution of a physical examination of a recently created AVF to assess its maturation.

\section{DUS Evaluation of AVF}

The AVF can be described as mature, by duplex ultrasound (DUS) examination, if the so-called rule of six criteria are respected: At 6 weeks post-creation, the diameter of the body of the AVF should be at least $6 \mathrm{~mm}$. The blood-flow rate should be $600 \mathrm{~mL} / \mathrm{min}$ or more by this time. The depth should not be more than 0.5 to $0.6 \mathrm{~cm}$. The AVF length should be 5 to $6 \mathrm{~cm}$ to allow for a successful two-needle dialysis. ${ }^{50}$

Apart from the rule of six criteria a detailed DUS examination is recommended to rule out the cause of early failure to plan the best tailored solution to treat the complication.
Table 3 Physical Examination of the Newly Created AVF

Inspection

- Assesses the wound and its correct healing of the AVF anastomosis.

- Inspect the body of the AVF to determine if it is visible and, if so, for what length (optimal length> $6 \mathrm{~cm}$ ).

- Evaluate the apparent diameter and depth to determine if it has the potential to be cannulated.

- Assess whether accessory veins are visible.

Palpation

- Normally, the thrill of the AVF anastomosis is perceptible to the touch as a vibration. The body of the AVF should be soft and easily compressible.

- If the thrill is not perceived, the AVF can be thrombosed.

- The thrill should disappear when the outflow vein is occluded manually more proximally due to the cessation of flow. If the thrill does not go away, an accessory vein is present distal to the occlusion point.

- When AVF is completely occluded manually, the arterial pulse distal to the AVF anastomosis must be increased. The degree of increase is directly proportional to the flow of the AVF.

- If AVF is hyperpulsive (an indication of outflow stenosis), the change in pulse produced by manual occlusion reflects the severity of the stenosis that is causing hyperpulsatility.

- To evaluate a possible iuxta-anastomotic stenosis it is useful to palpate the vein and artery distal to the anastomosis with the finger. In case of stenosis, the impulse disappears abruptly when the site of iuxtaanastomotic stenosis is encountered. Downstream the impulse will be weak or undetectable

Auscultation

- Auscultation of the bruit is useful for determining the character of the diastolic component of the flow. Normal finding is the low rumbling tone with a prominent diastolic component.

- In case of stenosis there is a progressive increase in resistance which makes the diastolic component disappear and the bruit becomes more acute.

Abbreviation: AVF, arteriovenous fistula.

The DUS examination of an AVF should be articulated with the study of the following segments:

- Inflow artery (including calculation of AVF blood flow)

- Anastomosis

- Outflow vein

The inflow artery (the one that provides the anastomosis) is usually dilated and consists of a thin 2-layer wall. The examination of the inflow artery begins in a proximal part of an arm. The course of the brachial artery and its bifurcation in the radial and ulnar arteries are evaluated. The 
Doppler spectral curve it is normally biphasic, low resistance, with continuous antegrade flow. The measurements to be obtained at this level and in the longitudinal scan are the mean average velocity over time (TAVM) and the brachial artery diameter both useful to calculate the flow rate $(\mathrm{mL} / \mathrm{min})$ of the vascular access.

Table 4 describes the modality of volume flow rate calculation.

In RC-AVF the radial artery is examined from the bifurcation to the anastomosis. Particular attention should be taken to identify possible radial artery stenosis.

As generally recommended, the treatment must be reserved for hemodynamically significant stenoses, so it is important to evaluate the percentage reduction of the lumen in addition to the brachial artery flow. ${ }^{3}$

The evaluation of the anastomosis should assess the presence of any stenosis. Generally, the morphologic and hemodynamic criteria drive the diagnosis, whereas calculation of the systolic velocity peak (greater than 3: 1 compared to the supply artery $2 \mathrm{~cm}$ upstream) could often be challenging and inaccurate. Therefore, a pure anastomotic significant stenosis - which rarely occurs isolated - would be suspected when the brachial artery flow volume is low, high resistive index spectral Doppler curve is observed,

Table 4 AVF Flow Calculation

\begin{tabular}{l} 
HOW and WHEN perform the examination \\
\hline The mean of three measure must be calculated but 5 is preferable in \\
patients with cardiac arrhythmias. \\
The examination should be performed in the interdialytic period to avoid \\
hemodynamic instability interferences deriving from the session itself. \\
\hline WHERE performs the measurement \\
\hline \begin{tabular}{l} 
Vascular access flow in native AVF should be measured in the brachial \\
artery, regardless of the artery that feeds the vascular access. \\
Irregular areas (stenosis etc.) should be kept at least $5 \mathrm{~cm}$ from the \\
sample volume site. \\
WHICH calculation runs \\
\hline $\begin{array}{l}\text { The calculation of the volume flow is based on the following equation: } \\
\text { QVA }=\pi \times r^{2} \times \text { TAVM. }\end{array}$ \\
TAVM represents the average speed of blood flow through the vessel \\
over time. \\
It is not appropriate to use the average maximum speed to calculate the \\
volume flow because this would overestimate the access flow since it \\
would only describe the major blood speed central to the vessel.
\end{tabular}
\end{tabular}

Abbreviations: AVF, arteriovenous fistula, QVA, vascular access blood flow, $r$, radius, TAVM, time average velocity. and any stenosis is found on both artery inflow and venous outflow along with a narrow anastomotic area.

The outflow vein must be examined through measurements of the minimum diameter, depth and length of the cannulation segment. These data will be used to evaluate maturation as to the rule of six criteria. It is also appropriate to identify the presence of any collateral vessels draining flow from the main stenosed conduit or the presence of extraluminal lesions (hematoma, seroma). ${ }^{51,52}$

\section{RCAVF Early Failure Common Scenarios: Stenosis and Thrombosis}

These are the most frequent causes of delayed maturation of AVF. Thrombosis usually is the consequence of: hypotension, thrombophilia, pre-existing stenosis or de novo because of a surgical drawback, compressing hematoma or wound infection, rarely excessive haemostatic compression.

Stenosis can lead to delayed maturation either because of the occurrence of thrombosis or because of the consequent low blood flow.

In a prospective study of 119 consecutive patients referred for non-maturing AVF, an angiograms were performed to detect the cause of AVF immaturity. ${ }^{53}$ Juxtaanastomotic stenosis was the most common lesion (64\%). This type of stenosis typically occurs in the outflow vein within $1-5 \mathrm{~cm}$ of the anastomosis sometimes at the site of the venous valves.

The reason why the most involved anatomical site is the post-anastomotic venous region is probably because it is the area most subject to surgical manipulation, flow turbulence and myo-intimal alteration. Stenosis/thrombosis affecting the central veins are less frequently, if ever, the cause of delayed maturation. The picture of central vein occlusion syndrome (swelling of the arm, collateral venous thoracic reticules), should be differentiated from true delayed maturation. Some claims the presence of accessory veins as a potential reason for insufficient maturation of the AVF, but the matter is still controversial. $^{44}$

As to treatment of the thrombosed access a review of comparative studies of percutaneous vs surgical thrombectomy suggest a benefit of traditional surgery in AVF, but does not reveal the definitive superiority of one technique compared to the other. ${ }^{54}$ As to stenosis treatment endovascular technique is the suggested approach for most of cases. ${ }^{55} \mathrm{~A}$ debate is ongoing whether for juxtaanastomotic stenosis the best solution is provided by angioplasty or surgical proximalization; in this context guidelines from the $\mathrm{ESVS}^{3}$ state that surgery may have 
advantage over angioplasty but evidence for a strong indication still lack. Angioplasty could be preferred when the shorten of the access conduit is a concern. A thorough description is detailed in Turmel Rodrigues article revising the technique. ${ }^{55}$

\section{RCAVF Pseudo-Delayed Maturation: Transposition and Lipectomy}

The pseudo-delayed maturation of the RCAVF makes the venipuncture of the angioaccess difficult if not impossible, due to its excessive depth under a thick subcutaneous adipose tissue; flow and diameter being both adequate as to rule of six.

The cause may be due to either anatomical conformation of the subject or because of obesity.

Superficialisation of a deep vein under the skin can be traditionally performed through transposition or elevation techniques. The principles of both techniques have been established for the creation of brachial-basilic AVF, few studies are available on RC-AVF. Bronder et $\mathrm{al}^{56}$ and Weyde et al, ${ }^{57}$ published the results after elevation in RCAVF. The primary and secondary patent rates were $60 \%$ and $70 \%$ at 1 year respectively. Vein elevation is performed through a longitudinal incision of the forearm. The procedure includes superficial vein mobilization, suture of subcutaneous tissues under the vein and skin closure over the elevated vein. For this reason, the vein is often immediately below the longitudinal incision making, especially in case of hypertrophic scars, cannulation difficult. Lipectomy is the alternative surgical technique for effective superficialisation according to the technique described by Bourquelot. ${ }^{58}$ In short, through 2 small transverse incisions, the subcutaneous tissue can be removed about $4 \mathrm{~cm}$ long on each side of each incision. Thus, this technique allows the removal of subcutaneous fat without the need to mobilize the vein. Results are rather encouraging since over 49 patients with an average BMI of $31 \pm$ $5.6 \mathrm{~kg} / \mathrm{m} 2$ the technical success rate (ability to palpate the vein under the skin) and clinical success rate (ability to perform at least three consecutive HD sessions) were $96 \%$ and $94 \%$ respectively. ${ }^{58}$

\section{Other Uncommon Causes of Early Failure}

The large hematomas are rare but, if they occur, may interrupt the anastomosis and lead to the need for surgical revision of access. The formation of a hematoma after surgery can be favoured by uncontrolled arterial hypertension, excessive use of antiplatelet or anticoagulant agents or inadequate haemostasis at the end of the intervention. To minimize bleeding risk and hematoma formation, patients who have already started HD should not be operated on for the first 24 hours after haemodialysis, or careful short-term intradialytic anticoagulation should be tailored perioperatively.

Another infrequent complication that can lead to early failure are infections, or collections of serum (seroma). Overall, they have an incidence $<1 \%$. In addition to medical (antibiotic) therapy aspirations or surgical revision are sometimes necessary.

Equally very rare for a maturing RCAVF is the haemodialysis access induced distal ischemia (HAIDI) syndrome which would necessitate sometimes access closure. $^{59}$

The most serious complication, although extremely rare in RCAVF, is ischemic monomelic neuropathy. It usually affects proximal fistulas and diabetic patients and is caused by inadequate vascularization of the vasa nervorum which leads to severe sensorimotor dysfunction of the radial, median and ulnar nerves without hand ischemia. It is an absolute indication of the immediate closure of the access. ${ }^{60}$

\section{New Approaches for Early Assessment of AVF Maturation}

Some studies have evaluated the intimal-medial thickness (IMT) of the venous wall as an early parameter of AVF maturation. However, this approach requires the use of high frequency ultrasound $(>30 \mathrm{MHz})$, which is not always available. ${ }^{49}$

The measurement of intraoperative access blood flow provided by DUS would also provide valuable information on AVF maturation. ${ }^{61}$ Berman et al has verified that intraoperative blood flow measurements obtained during the construction of the AVF can identify those access that will not mature. ${ }^{62}$ Specifically, there was a significant difference in intraoperative flows between AVF that matured $(573.6 \pm 103 \mathrm{~mL} / \mathrm{min})$ compared to AVF that did not mature $(216.8 \pm 35.8 \mathrm{~mL} / \mathrm{min})$. Similarly, early postoperative flow measurement - on the first day after surgery or up to 14 days postoperatively - was highly predictive of the primary patency of the RC-AVF. ${ }^{63}$

These early data seem to have a higher predictive potential for AVF maturation, compared to the standard flow measurement at 6 weeks after-surgery, even if a definitive indication for daily practice still lack. 
L.M. Rosales and colleagues measured central venous oxygen saturation (ScvO2) levels in HD CVC-carrying patient's candidates for AVF surgery. ${ }^{64}$

In patients with successful AVF maturation, $\mathrm{ScvO} 2$ increased by $20 \%$ one week after the creation of the access. No increase occurred in patients where AVF maturation failure occurred. These and other studies ${ }^{65}$ have been performed on a small sample of patients. Further investigation is needed to evaluate the real utility of $\mathrm{ScvO} 2$ as a premature parameter of AVF maturation.

\section{Improve the Maturation of the AVF: Future Directions}

Promoting access maturation without resulting in an exuberant vessel wall thickening is the current challenge. Preclinical and clinical studies have analysed and tried to overcome the phenomenon of neointimal hyperplasia, improve vessel dilation and interfere with blood clotting processes, including - but not limited to - use of clopidogrel, statins, fish oil or aspirin. Most of these medications have failed. Currently, the guidelines do not recommend these drugs to improve the maturation/patency of the AVF, as already mentioned above. These products aimed to improve the fistula's maturation process by reducing, as a preventive measure, tissue inflammation or coagulation processes. Some new strategies consider post-creation approaches (procedures applied after the creation of the AVF) to improve maturation of RCAVF.

The main mechanisms under study are:

- pharmacological substances (Sirolimus)

- products based on elastase (Vonapanitase)

- allogeneic endothelial cells in polymeric systems (Vascugel)

- mechanical support devices (VasQ ${ }^{\mathrm{TM}}$ and Optiflow ${ }^{\mathrm{TM}}$ )

- infrared therapy

- gene therapy

Sirolimus is an antiproliferative drug. It is currently used for suppression of the growth of neointimal tissue in coronary artery disease when administered locally by an endovascular drug-eluting stent. In the field of vascular access, innovative products are under examination as collagen membranes with local release of sirolimus ( $\mathrm{SeCM}$ ) for the drug's intraoperative perivascular administration, but these products are still in the pre-clinical study phase. A study exists on AV graft on 12 HD patients enrolled for evaluating the effect of sirolimus-releasing collagen membrane (Coll-R). At 24 month of follow-up no adverse events related to Coll- $R$ have occurred. The blood concentrations of sirolimus were sub-therapeutic for immunosuppression. Primary unassisted patency at 12 and 24 months were 76 and $38 \%$, respectively.

Vonapanitase (formerly PRT-201) is a recombinant elastase human like chymotrypsin. The application of vonapanitase immediately after creating the AVF have been tested to increase the AVF patency and prevent the formation of critical stenosis.

The double-blind controlled study of 349 PATENCY 1 patients (NCT02110901) showed no significant improvement in primary patency but revealed an increase in the secondary patency rate. In the double-blind, randomized multicenter study of 603 patients (PATENCY-2), vonapanitase solution was applied at the time of the creation of RC-AVF. In April 2019, Proteon Therapeutics (Waltham, MA) reported that the study did not reach statistical significance in primary or secondary patency. ${ }^{66}$

Vascugel (Pervasis Therapeutics, Inc., Cambridge, MA) is a product that uses differentiated adult allogeneic endothelial cells embedded in a patented polymer matrix system. The product is placed on the external vascular walls after the creation of an AVF. Vascugel endothelial cells provide endothelial regulatory compounds' growth by promoting healing and reducing inflammation and intimal hyperplasia. The V-HEALTH study, including 57 patient, showed how after 4 to 8 weeks, Vascugel was spontaneously reabsorbed without creating intolerance or complications. Statistical significance however was not achieved in terms of improving patency. ${ }^{67}$

Far infrared therapy (FIR) uses electromagnetic waves aiming at improving blood flow and endothelial function. A wavelength between 5 and $25 \mathrm{mcm}$ is applied by a distant infrared wave emitted in position about $20 \mathrm{~cm}$ above the AVF anastomosis, for as long as 40-minute during each HD treatment. FIR therapy has been tested for AVF occlusion rates, blood flow level, AVF diameter, primary patency and needle pain levels. ${ }^{68,69}$ Definite results and clinical indication are in wait.

Mechanical support devices can optimize the geometry of the fistula anastomosis to prevent or delay neointimal hyperplasia. VasQ ${ }^{\mathrm{TM}}$ and Optiflow ${ }^{\mathrm{TM}}$ devices have been the most studied with encouraging results regarding safety and technical success, such as maturation rates and longterm patency, further studies are needed to confirm the firsts reports. ${ }^{70-73}$ 
Genetic therapy is an innovative and fascinating topic. Several genetic polymorphisms predispose to access failure. The most important are associated with endothelial damage (NOs) and the increased thrombotic risk such as VEGF-A, factor V, methylenetetrahydrofolate (MTHFR), HO-1, TGF $\beta-1$ and klotho (KL).

The most promising factor in targeted genetic therapy for AVF is VEGF-A. Low-dose VEGF-A promotes the vasodilation process by inducing NOs and prostacyclin and suppressing smooth muscle cells' proliferation. In contrast, high concentrations of VEGF-A promote angiogenesis. The increased gene expression of VEGF is associated with an increased risk of AVF thrombosis. As evidence of this, factors inhibiting the endothelial expression of VEGF-A (lentivirus) have allowed the reduction of the concentric remodeling process, reaching a better rate of patency of the AVF in mouse models. Although gene therapy in AVF maturation is an emerging topic, it remains far from clinical application. ${ }^{74,75}$

\section{Conclusions}

RC-AVF, which is the gold standard angioaccess for HD, suffers from a relatively high rate of non-maturation, affecting the morbidity of HD patients. The success of the maturation is strictly correlated to the monitoring of access at various times. Apart from a proper pre-surgical planning of the vascular access, AVF monitoring begins immediately during surgery and continues in the postoperative period through close surveillance in the first weeks useful for an early correction of complications. In all these steps medical and nursing scrutiny must be intense. Few studies have focused on new AVF monitoring techniques and ultrasound remains the most useful tool in daily clinical practice. Strategies to promote RC-AVF maturation performed mostly through the administration of pre or peri-operative drugs have not proved to be effective in improving the success of the fistula. New techniques being tested post-access surgery appear to represent a future promise for fistula maturation enhancement. Research in the field of AVF monitoring techniques and new systems to promote maturation should be encouraged. Currently, their application remains not yet scheduled in clinical practice programs for AV care.

\section{Disclosure}

The authors report no conflicts of interest in this work.

\section{References}

1. Zavacka M, Zelko A, Madarasova Geckova A, Majernikova M, Pobehova J, Zavacky P. Vascular access as a survival factor for the haemodialysis population: a retrospective study. Int Angiol. 2020;39 (6):525-531. doi:10.23736/S0392-9590.20.04401-6

2. Lok CE, Huber TS, Lee T, et al. KDOQI clinical practice guideline for vascular access: 2019 update. Am J Kidney Dis. 2020;75:S1S164.

3. Schmidli J, Widmer MK, Basile C, et al. Vascular access: 2018 clinical practice guidelines of the European society for vascular surgery (ESVS) 5. Eur J Vasc Endovasc Surg. 2018.

4. Gallieni M, Hollenbeck M, Inston N, et al. Clinical practice guideline on peri- and postoperative care of arteriovenous fistulas and grafts for haemodialysis in adults. Nephrol Dial Transplant. 2019;34(Supp12): ii1-ii42. doi:10.1093/ndt/gfz072

5. Idrees M, Suthananthan A, Pathmarajah T, Sieunarine K. Snuffbox fistula - a first-line approach to haemodialysis: a review. J Vasc Access. 2020;21 (5):1129729819867817. doi:10.1177/1129729819867817

6. Bourquelot P, Rawa M, Van Laere O, Franco G. Long-term results of femoral vein transposition for autogenous arteriovenous hemodialysis access. J Vasc Surg. 2012;56(2):440-445. doi:10.1016/j.jvs.2012.01.068

7. Karam L, Rawa M, Shoenfeld R, Bourquelot P. Brachial vein transposition is a promising ultimate upper limb autologous arteriovenous angioaccess despite its many pitfalls. J Vasc Surg. 2018;67(1): 236-243. doi:10.1016/j.jvs.2017.05.120

8. Pham XD, Kim JJ, Ihenachor EJ, et al. A comparison of brachial artery-brachial vein arteriovenous fistulas with arteriovenous grafts in patients with poor superficial venous anatomy. J Vasc Surg. 2017;65 (2):444-451. doi:10.1016/j.jvs.2016.09.037

9. Fitts MK, Pike DB, Anderson K, Shiu YT. Hemodynamic shear stress and endothelial dysfunction in hemodialysis access. Open Urol Nephrol J. 2014;7(Supp11 M5):33-44. doi:10.2174/1874303X014 07010033

10. Chan CY, Chen YS, Ma MC, Chen CF. Remodeling of experimental arteriovenous fistula with increased matrix metalloproteinase expression in rats. J Vasc Surg. 2007;45(4):804-811. doi:10.1016/j.jvs.20 06.12 .063

11. Corpataux JM, Haesler E, Silacci P, Ris HB, Hayoz D. Low-pressure environment and remodelling of the forearm vein in Brescia-Cimino haemodialysis access. Nephrol Dial Transplant. 2002;17(6):10 57-1062. doi:10.1093/ndt/17.6.1057

12. Remuzzi A, Bozzetto M. Biological and physical factors involved in the maturation of arteriovenous fistula for hemodialysis. Cardiovasc Eng Technol. 2017;8(3):273-279. doi:10.1007/s13239-017-0323-0

13. Remuzzi A, Bozzetto M, Brambilla P. Is shear stress the key factor for AVF maturation? J Vasc Access. 2017;18(Suppl.1):10-14. doi:10.5301/jva.5000686

14. Nath KA, Katusic ZS. Predicting the functionality and form of a dialysis fistula. J Am Soc Nephrol. 2016;27(12):3508-3510. doi:10.1681/ASN.2016050569

15. Zhao J, Jourd'heuil FL, Xue M, et al. Dual function for mature vascular smooth muscle cells during arteriovenous fistula remodeling. J Am Heart Assoc. 2017;6(4). doi:10.1161/JAHA.11 6.004891

16. Browne LD, Bashar K, Griffin P, Kavanagh EG, Walsh SR, Walsh MT. The role of shear stress in arteriovenous fistula maturation and failure: a systematic review. PLoS One. 2015;10(12):e0145795. doi:10.1371/journal.pone. 0145795

17. Hammes M. Hemodynamic and biologic determinates of arteriovenous fistula outcomes in renal failure patients. Biomed Res Int. 2015;2015:171674. doi:10.1155/2015/171674

18. Santos Epifânio AP, Balbino KP, Jorge MP, et al. Metabolic, inflammatory and oxidative stress markers in the nitric oxide variation of hemodialysis subjects. Nutr Hosp. 2018;35(1):176-184. doi:10.20 960/nh.1319 
19. Tong X, Hou X, Wason C, Kopel T, Cohen RA, Dember LM. Smooth muscle nitric oxide responsiveness and clinical maturation of hemodialysis arteriovenous fistulae. Am J Pathol. 2017;187(9):2095-2101. doi:10.1016/j.ajpath.2017.05.006

20. Srivastava A, Mittal V, Lal H, et al. Spiral laminar flow, the earliest predictor for maturation of arteriovenous fistula for hemodialysis access. Indian J Urol. 2015;31(3):240-244. doi:10.4103/0970-1591.159650

21. Gameiro J, Ibeas J. Factors affecting arteriovenous fistula dysfunction: a narrative review. J Vasc Access. 2020;21(2):134-147. doi:10.1177/1129729819845562

22. Conte MS, Nugent HM, Gaccione P, Roy-Chaudhury P, Lawson JH. Influence of diabetes and perivascular allogeneic endothelial cell implants on arteriovenous fistula remodeling. J Vasc Surg. 2011;54 (5):1383-1389. doi:10.1016/j.jvs.2011.05.005

23. Lazarides MK, Georgiadis GS, Antoniou GA, Staramos DN. A meta-analysis of dialysis access outcome in elderly patients. $J$ Vasc Surg. 2007;45(2):420-426. doi:10.1016/j.jvs.2006.10.035

24. Astor BC, Coresh J, Powe NR, Eustace JA, Klag MJ. Relation between gender and vascular access complications in hemodialysis patients. $\mathrm{Am}$ J Kidney Dis. 2000;36(6):1126-1134. doi:10.1053/ajkd.2000.19816

25. Mendes RR, Farber MA, Marston WA, Dinwiddie LC, Keagy BA, Burnham SJ. Prediction of wrist arteriovenous fistula maturation with preoperative vein mapping with ultrasonography. J Vasc Surg. 2002;36(3):460-463. doi:10.1067/mva.2002.126544

26. Siddiqui MA, Ashraff S, Santos D, Rush R, Carline T, Raza Z. Predictive parameters of arteriovenous fistula maturation in patients with end-stage renal disease. Kidney Res Clin Pract. 2018;37 (3):277-286. doi:10.23876/j.krcp.2018.37.3.277

27. Brimble KS, Rabbat CG, Treleaven DJ, Ingram AJ. Utility of ultrasonographic venous assessment prior to forearm arteriovenous fistula creation. Clin Nephrol. 2002;58(2):122-127. doi:10.5414/cnp58122

28. Pirozzi N, Apponi F, Napoletano AM, Luciani R, Pirozzi V, Pugliese F. Microsurgery and preventive haemostasis for autogenous radial-cephalic direct wrist access in adult patients with radial artery internal diameter below $1.6 \mathrm{~mm}$. Nephrol Dial Transplant. 2010;25 (2):520-525. doi:10.1093/ndt/gfp452

29. Ene-Iordache B, Cattaneo L, Dubini G, Remuzzi A. Effect of anastomosis angle on the localization of disturbed flow in 'side-to-end' fistulae for haemodialysis access. Nephrol Dial Transplant. 2013;28 (4):997-1005. doi:10.1093/ndt/gfs298

30. Rongrong W, Li D, Guangqing Z, Xiaoyin C, Kun B. The effects of iontophoretic injections of salvia miltiorrhiza on the maturation of the arteriovenous fistula: a randomized, controlled trial. Altern Ther Health Med. 2016;22(5):18-22.

31. Viecelli AK, Mori TA, Roy-Chaudhury P, et al. The pathogenesis of hemodialysis vascular access failure and systemic therapies for its prevention: optimism unfulfilled. Semin Dial. 2018;31(3):244-257. doi:10.1111/sdi.12658

32. Viecelli AK, Polkinghorne KR, Pascoe EM, et al. Fish oil and aspirin effects on arteriovenous fistula function: secondary outcomes of the randomised omega-3 fatty acids (Fish oils) and Aspirin in Vascular access OUtcomes in REnal Disease (FAVOURED) trial. PLoS One. 2019;14(3):e0213274. doi:10.1371/journal.pone.0213274

33. Smith GE, Souroullos P, Cayton T, Harwood A, Carradice D, Chetter IC. A systematic review and meta-analysis of systemic intraoperative anticoagulation during arteriovenous access formation for dialysis. $J$ Vasc Access. 2016;17(1):1-5. doi:10.5301/jva.5000484

34. Andreucci VE, Fissell RB, Bragg-Gresham JL, et al. Dialysis outcomes and practice patterns study (DOPPS) data on medications in hemodialysis patients. Am J Kidney Dis. 2004;44(5 Suppl 2):61-67. doi:10.1053/j.ajkd.2004.08.013

35. Chen FA, Chien CC, Chen YW, Wu YT, Lin CC. Angiotensin converting-enzyme inhibitors, angiotensin receptor blockers, and calcium channel blockers are associated with prolonged vascular access patency in uremic patients undergoing hemodialysis. PLoS One. 2016;11(11):e0166362. doi:10.1371/journal.pone.0166362
36. Salimi F, Majd Nassiri G, Moradi M, et al. Assessment of effects of upper extremity exercise with arm tourniquet on maturity of arteriovenous fistula in hemodialysis patients. J Vasc Access. 2013;14 (3):239-244. doi:10.5301/jva.5000123

37. Fontseré N, Mestres G, Yugueros X, et al. Effect of a postoperative exercise program on arteriovenous fistula maturation: a randomized controlled trial. Hemodial Int. 2016;20(2):306-314. doi:10.1111/ hdi. 12376

38. Tordoir JHM, Zonnebeld N, van Loon MM, Gallieni M, Hollenbeck M. Surgical and endovascular intervention for dialysis access maturation failure during and after arteriovenous fistula surgery: review of the evidence. Eur J Vasc Endovasc Surg. 2018;55 (2):240-248. doi:10.1016/j.ejvs.2017.12.001

39. Rooijens PP, Tordoir JH, Stijnen T, Burgmans JP, Yo TI. Radiocephalic wrist arteriovenous fistula for hemodialysis: meta-analysis indicates a high primary failure rate. Eur $J$ Vasc Endovasc Surg. 2004;28(6):583-589. doi:10.1016/j.ejvs.2004.08.014

40. Nordyke RJ, Reichert H, Bylsma LC, et al. Costs attributable to arteriovenous fistula and arteriovenous graft placements in hemodialysis patients with medicare coverage. Am J Nephrol. 2019;50 (4):320-328. doi:10.1159/000502507

41. Muray Cases S, García Medina J, Pérez Abad JM, et al. Importance of monitoring and treatment of failed maturation in radiocephalic arteriovenous fistula in predialysis: role of ultrasound. Nefrologia. 2016;36(4):410-417. doi:10.1016/j.nefro.2015.10.016

42. Li H, Jen S, Ramayya T, Bowers HG, Rotem E. Unanticipated late maturation of an arteriovenous fistula after creation of separate graft access. Quant Imaging Med Surg. 2018;8(4):444-446. doi:10.21037/ qims.2018.01.03

43. Lee T, Ullah A, Allon M, et al. Decreased cumulative access survival in arteriovenous fistulas requiring interventions to promote maturation. Clin J Am Soc Nephrol. 2011;6(3):575-581. doi:10.2215/CJN.06630810

44. Beathard GA, Arnold P, Jackson J, Litchfield T. Aggressive treatment of early fistula failure. Kidney Int. 2003;64(4):1487-1494. doi:10.1046/j.1523-1755.2003.00210.x

45. Beathard GA, Berns JS, Eidt JF et al. Maturation and evaluation of the newly created hemodialysis arteriovenous fistula. 2016

46. Robbin ML, Greene T, Cheung AK, et al. Arteriovenous fistula development in the first 6 weeks after creation. Radiology. 2016;279(2):620-629. doi:10.1148/radiol.2015150385

47. Leon C, Asif A. Physical examination of arteriovenous fistulae by a renal fellow: does it compare favorably to an experienced interventionalist? Semin Dial. 2008;21(6):557-560. doi:10.1111/ j.1525-139X.2008.00477.x

48. Robbin ML, Chamberlain NE, Lockhart ME, et al. Hemodialysis arteriovenous fistula maturity: US evaluation. Radiology. 2002;225 (1):59-64. doi:10.1148/radiol.2251011367

49. Leon C, Orozco-Vargas LC, Krishnamurthy G, et al. Accuracy of physical examination in the detection of arteriovenous graft stenosis. Semin Dial. 2008;21(1):85-88. doi:10.1111/j.1525-139X.2007.00382.x

50. Access BV. Clinical practice recommendations for needling of arteriovenous fistulae and grafts for haemodialysis. 2018.

51. Kosa SD, Al-Jaishi AA, Moist L, Lok CE. Preoperative vascular access evaluation for haemodialysis patients. Cochrane Database Syst Rev. 2015;9:CD007013. doi:10.1002/14651858.CD007013.pub2

52. Pirozzi N, Giuliani A, Scrivano J, et al. Echographic landmark of cephalic and collateral accessory vein at forearm in preoperative evaluation for hemodialysis angioaccess. $J$ Vasc Access. 2015;16 (5):364-366. doi:10.5301/jva.5000443

53. Nassar GM. Endovascular management of the "failing to mature" arteriovenous fistula. Tech Vasc Interv Radiol. 2008;11(3):175-180. doi:10.1053/j.tvir.2008.09.004

54. Tordoir JH, Bode AS, Peppelenbosch N, van der Sande FM, de Haan MW. Surgical or endovascular repair of thrombosed dialysis vascular access: is there any evidence? J Vasc Surg. 2009;50(4):9 53-956. doi:10.1016/j.jvs.2009.06.058 
55. Turmel-Rodrigues LA. Mechanical enhancement of AVF maturation. J Vasc Access. 2014;15(Suppl 7):S55-S59. doi:10.5301/jva.5000232

56. Bronder CM, Cull DL, Kuper SG, et al. Fistula elevation procedure: experience with 295 consecutive cases during a 7-year period. $J \mathrm{Am}$ Coll Surg. 2008;206(5):1076-81; discussion 1081-2. doi:10.1016/j. jamcollsurg.2007.12.030

57. Weyde W, Krajewska M, Letachowicz W, Klinger M. Superficialization of the wrist native arteriovenous fistula for effective hemodialysis vascular access construction. Kidney Int. 2002;61 (3):1170-1173. doi:10.1046/j.1523-1755.2002.00202.x

58. Bourquelot P, Tawakol JB, Gaudric J, et al. Lipectomy as a new approach to secondary procedure superficialization of direct autogenous forearm radial-cephalic arteriovenous accesses for hemodialysis. J Vasc Surg. 2009;50(2):369-74, 374.e1. doi:10.1016/ j.jvs.2009.03.009

59. Inston N, Schanzer H, Widmer M, et al. Arteriovenous access ischemic steal (AVAIS) in haemodialysis: a consensus from the Charing Cross Vascular Access Masterclass 2016. J Vasc Access. 2017;18(1):3-12. doi:10.5301/jva.5000621

60. Thimmisetty RK, Pedavally S, Rossi NF, Fernandes JAM, Fixley J. Ischemic monomelic neuropathy: diagnosis, pathophysiology, and management. Kidney Int Rep. 2017;2(1):76-79. doi:10.1016/j. ekir.2016.08.013

61. Johansson M, Myredal A, Friberg P, Gan LM. High-resolution ultrasound showing increased intima and media thickness of the radial artery in patients with end-stage renal disease. Atherosclerosis. 2010;211(1):159-163. doi:10.1016/j.atherosclerosis.2010.01.031

62. Berman SS, Mendoza B, Westerband A, Quick RC. Predicting arteriovenous fistula maturation with intraoperative blood flow measurements. J Vasc Access. 2008;9(4):241-247. doi:10.1177/ 112972980800900404

63. Ladenheim ED, Lulic D, Lum C, Agrawal S, Chadwick N. Firstweek postoperative flow measurements are highly predictive of primary patency of radiocephalic arteriovenous fistulas. $J$ Vasc Access. 2016;17(4):307-312. doi:10.5301/jva.5000544

64. Rosales LM, Zhang H, Mateo M, et al. Tracking arteriovenous fistula maturation: a novel approach. Blood Purif. 2019;47(1-3):240-245. doi:10.1159/000494742

65. Rotondi S, Tartaglione L, Muci ML, Pasquali M, Pirozzi N, Mazzaferro S. A new technique for measuring fistula flow using venous blood gas oxygen saturation in patients with a central venous catheter. Clin Kidney J. 2020;13(2):184-187. doi:10.1093/ckj/sfz064
66. Bleyer AJ, Scavo VA, Wilson SE, et al. A randomized trial of vonapanitase (PATENCY-1) to promote radiocephalic fistula patency and use for hemodialysis. J Vasc Surg. 2019;69(2):507-515. doi:10. 1016/j.jvs.2018.04.068

67. Conte MS, Nugent HM, Gaccione P, Guleria I, Roy-Chaudhury P, Lawson JH. Multicenter Phase I/II trial of the safety of allogeneic endothelial cell implants after the creation of arteriovenous access for hemodialysis use: the V-HEALTH study. J Vasc Surg. 2009;50 (6):1359-68.e1. doi:10.1016/j.jvs.2009.07.108

68. Hadimeri U, Wärme A, Stegmayr B. A single treatment, using Far Infrared light improves blood flow conditions in arteriovenous fistula. Clin Hemorheol Microcirc. 2017;66(3):211-217. doi:10.3233/CH170254

69. Wan Q, Yang S, Li L, Chu F. Effects of far infrared therapy on arteriovenous fistulas in hemodialysis patients: a meta-analysis. Ren Fail. 2017;39(1):613-622. doi:10.1080/0886022X.2017.1361835

70. Nikam M, Chemla ES, Evans J, et al. Prospective controlled pilot study of arteriovenous fistula placement using the novel Optiflow device. J Vasc Surg. 2015;61(4):1020-1025. doi:10.1016/j.jvs.20 14.11.082

71. Chemla E, Tavakoli A, Nikam M, et al. Arteriovenous fistula creation using the Optiflow ${ }^{\mathrm{TM}}$ vascular anastomotic connector: the OPEN (Optiflow PatEncy and MaturatioN) study. J Vasc Access. 2014;15 (1):38-44. doi:10.5301/jva.5000169

72. Shahverdyan R, Meyer T, Matoussevitch V. Patency and functionality of radiocephalic arteriovenous fistulas with an external support device (VasQ ${ }^{\mathrm{TM}}$ ): real-world single-center experience. $J$ Vasc Access. 2020;1129729820904599. doi:10.1177/1129729820904599

73. Karydis N, Bevis P, Beckitt T, Silverberg D, Halak M, Calder F. An implanted blood vessel support device for arteriovenous fistulas: a randomized controlled trial. Am J Kidney Dis. 2020;75(1):45-53. doi:10.1053/j.ajkd.2019.05.023

74. Chen YW, Wu YT, Lin JS, et al. Association of genetic polymorphisms of renin-angiotensin-aldosterone system-related genes with arterio-venous fistula malfunction in hemodialysis patients. Int J Mol Sci. 2016;17(6). doi:10.3390/ijms17060833

75. Fekih-Mrissa N, Sayeh A, Baffoun A, et al. Association between thrombophilic gene mutations and the risk of vascular access thrombosis in hemodialysis patients. Ther Apher Dial. 2016;20(2):107-111. doi:10.1111/1744-9987.12379
Vascular Health and Risk Management

\section{Publish your work in this journal}

Vascular Health and Risk Management is an international, peerreviewed journal of therapeutics and risk management, focusing on concise rapid reporting of clinical studies on the processes involved in the maintenance of vascular health; the monitoring, prevention and treatment of vascular disease and its sequelae; and the involvemen of metabolic disorders, particularly diabetes. This journal is indexed on PubMed Central and MedLine. The manuscript management system is completely online and includes a very quick and fair peerreview system, which is all easy to use. Visit http://www.dovepress. com/testimonials.php to read real quotes from published authors. 